\title{
MARX Y LA ABOLICIÓN DEL TRABAJO ASALARIADO
}

Fernando Hugo Azcurra

Universidad de Buenos Aires (UBA)

\section{RESUMEN}

En la presente ponencia se busca señalar que el trabajo teórico de Marx respecto del trabajo asalariado como fundamento de la sociedad burguesa y del capital, no ha sido tomado en toda su dimensión clave para la construcción del socialismo en los países que lograron tomar el poder e iniciar su construcción. Hay un objetivo ausente que se ha transformado en una deuda pendiente: la abolición del trabajo asalariado que forma parte indisociable de la teoría económica de Marx. Los ejemplos históricos fallidos de construcción socialista muestran dramáticamente que no hay socialismo sin abolición del trabajo asalariado, objetivo que ha estado y está ausente en los movimientos políticos marxistas, sean o no revolucionarios, y que, además, esclarece la vinculación entre los conceptos teóricos como "relaciones de producción" y "modo de producción" de manera tal que este último no se modifique, respecto del capitalismo, aunque haya habido una variación en el anterior concepto (relaciones de producción).

Palabras claves: trabajo asalariado; abolición; socialismo; capitalismo; relaciones de producción; modos de producción; trabajo asociado. 


\section{Teoría del trabajo asalariado}

\section{1.- La relación económica específica entre trabajadores y capitalistas}

L

a teoría de Marx enseña que la condición estructural de la relación productiva entre el trabajador "libre" y la posición del propietario de los medios de producción

bajo la forma productiva y social específicamente capitalista es una relación de producción resultado de toda una larga etapa histórica de luchas, robos, confiscaciones, estafas, deudas, etc. (acumulación originaria) para subordinar los trabajadores al capital, que se va gestando en el seno de la sociedad feudal. El capital, primero se monta formalmente en los modos existentes de trabajo y producción en la Europa occidental y las va socavando; luego, poco a poco, se vuelve realmente dominante con su propia técnica quedando el proceso de producción/reproducción bajo el comando directo del capitalista. Se constituye así el modo específicamente capitalista de producción.

Que el trabajador sea "libre" significa que es propietario de su fuerza de trabajo, y lo es en tanto diferenciación de las formas de producción anteriores conocidas, las de trabajo esclavo y trabajo servil. Bajo el capitalismo ya no existen aquellas formas de subordinación personal en las relaciones de producción en las que el trabajador carece de entidad autónoma como sujeto de contrato por tanto como ente de juridicidad. Si éstas fueran las condiciones entonces no habría posibilidad alguna de relaciones capitalistas. El capital exige la contraposición de trabajadores que se presenten como "dueños" de lo que venden, no sea que alguien pudiera reclamar para sí la propiedad de aquellos e impidan la formalización contractual.

Los trabajadores, entonces, se ven obligados a "ofrecer" sus capacidades productivas también denominadas fuerza de trabajo $(\mathrm{Ft})$ (buscar empleo; ofrecer su trabajo) a las empresas para poder sostenerse como individuos. Como familia y como clase funciona la coacción económica. A los trabajadores en esta transacción mercantil les interesa: primero vender para comprar, esto es, vender el uso de su fuerza de trabajo (mercancía), percibir un salario (dinero) para luego con él adquirir los productos para su consumo (mercancía), se trata de una circulación simple mercancías y dinero. El circuito 
es pues mercancía-dinero-mercancía ( $\boldsymbol{m}-\boldsymbol{d}-\boldsymbol{m})$. Esto señala la segunda circunstancia: los trabajadores necesitan acceder a los valores de uso mercantiles sin los cuales no podrían subsistir ni ellos ni su familia.

El interés de los empresarios capitalistas es sólo comprar para vender. Compran con dinero (en realidad invierten y reinvierten) medios de producción (Mp) y el uso de la fuerza de trabajo; reúne a ambos en el proceso de producción mediante el cual obtiene una masa de mercancías valorizadas que venden recuperando la inversión acrecentada en un plus o excedente. El circuito es dinero-mercancía-dinero $(\boldsymbol{d}-\boldsymbol{m}-\boldsymbol{d}+\boldsymbol{\Delta} \boldsymbol{d})$.

La forma particular del cambio, en definitiva, es entre trabajadores y capitalistas que son los sujetos reales, no entre "trabajo" y "capital", relación que objetiva una diferenttia specifica respecto del trueque y del cambio entre mercancía por dinero: en principio se trata de una relación monetaria o económica, o sea que no es de subordinación personal como en las formas históricas anteriores y, en segundo lugar el dinero bajo la forma del pago salarial adquiere el derecho de uso por parte de los empresarios sobre el trabajo vivo y la jornada laboral de los trabajadores.

\section{2.- Condiciones generales del cambio trabajo asalariado/capital (Tw/K)}

El presupuesto fundamental de toda la relación de intercambio entre el trabajador asalariado y el empresario capitalista, consiste en la separación, escisión, entre la propiedad de los medios de producción y los trabajadores. Disociación, pues, entre condiciones objetivas y condiciones subjetivas de producción. Ahora bien, dice Marx que “La naturaleza no produce por una parte poseedores de dinero o de mercancías y por otra personas que simplemente poseen sus propias fuerzas de trabajo. Esta relación en modo alguno pertenece al ámbito de la historia natural, ni tampoco es una relación social común a todos los períodos históricos". (K. Marx, El Capital, Siglo XXI Editores, Bs. As. I, 1, p. 206) La disociación entre propiedad y trabajo se presenta como la ley necesaria del intercambio entre el capital y el trabajo. Constituye, pues, una relación específica, histórica, de este modo de producción. Entonces: 
a) La relación entre capitalista y trabajador no es de subordinación personal. La relación subordinada del trabajador al capitalista no es coacción de carácter extraeconómico como es el caso de los trabajos servil o esclavo de otras sociedades de clase.

b) La relación de subordinación es de carácter económico, surge de la asimetría en la organización social del trabajo: trabajadores no propietarios y propietarios no trabajadores. Esta es la base de la coacción económica. Los trabajadores están "liberados" de la propiedad de los medios de vida y de producción y los capitalistas están "liberados" de trabajar para mantenerse y vivir.

c) Se trata de una relación económica-laboral mediada por el dinero.

d) La relación es la de un intercambio que corresponde a la circulación simple de mercancías: cada uno de los tratantes obtiene un equivalente por lo que entrega; el trabajador recibe dinero bajo la forma de salario, el capitalista compra el derecho de usar la capacidad de trabajo de aquél.

e) La relación de subordinación del trabajador al capitalista la ejerce éste por medio del trabajo objetivado, dinero, medios de producción y medios de vida que constituyen "su propiedad" y de los cuales está despojado aquél. Pero en lo inmediato el dominio del trabajador se realiza por el dinero como inversión del capitalista y no en cuanto dinero mismo, es el dinero en función de capital y no de gasto.

\section{3.- Los dos momentos de la relación $\mathrm{Tw} / \mathrm{K}$}

Esta relación de cambio entre trabajador y capitalista se compone de dos momentos o procesos que deben determinarse de manera precisa: $\left.1^{\circ}\right)$ momento formal; $\left.2^{\circ}\right)$ momento real.

El momento formal y el momento real, que el capital y la economía burguesa no distinguen, en realidad es sólo un tipo de cambio entre trabajadores y capitalistas en el cual el momento formal funciona como velo (opacidad) del momento real. El primer momento expresa la relación contractual: compra de la fuerza de trabajo; el segundo se refiere al trabajo en proceso, a la actividad misma de producción y por este medio la

Cadernos GPOSSHE On-line, Fortaleza, v. 2, n. Especial, 2019. 
transformación inmediata del trabajo vivo en generadora de excedente (plus), que es su objetivación como realización del capital que produce capital por medio de la explotación económica de los trabajadores.

El momento formal se superpone al real y se muestra como el único intercambio; el cambio real entre trabajo vivo y trabajo objetivado queda subsumido en aquél como cumplimiento "equitativo" del contrato por parte del trabajador, funciona de este modo como un velo real que la realidad inmediata de la transacción muestra como transparente, sin señales de engaño alguno o fraude, sin muestras de opacidad ni de deformación.

\section{4.- La especificidad de la relación en los países socialistas.}

Pues bien, todas estas singularidades que caracterizan con precisión la explotación de la fuerza de trabajo por el capital y por tanto la subordinación del trabajador a los capitalistas, si las analizamos con atención, son claramente similares a lo que esencialmente sucedió con la clase trabajadora en la URSS. Se estructuró y subsistió la separación entre las condiciones subjetivas y objetivas bajo una nueva modalidad: la de la concentración de las condiciones objetivas, no sólo en un polo, sino en un único propietario (PCUS-Estado), que repetían su condición de capital aunque ya no hubiera capitalistas; podría pensarse en que el proceso de "colectivización" del agro (década del 30) desmentiría esto, pero sin embargo este proceso no fue otra cosa que una gigantesca y acelerada "expropiación" del campesinado ruso, lo que dio lugar a que formalmente existiera la propiedad cooperativa, pero realmente estaba atada y subordinada a la dirección y los planes del partido-Estado. Y fue esta peculiar forma social de producción la que constituiría la base de los acontecimientos histórico-políticos de la década del 90 en la URSS y en los países europeos socialistas.

Esta monopolización de los medios de producción en el Estado-PCUS como único capitalista en un polo, determinó la continuación de la expropiación de los trabajadores y el mantenimiento de la relación de trabajo asalariada como el otro polo de una contraposición antagónica. Este tipo de construcción socialista actuó y actúa como "paradigma" en los procesos de construcciones que en lugar de desembocar en 
una nueva sociedad lo que hace es "recrear" las condiciones burguesas de producción y alentar el surgimiento de una clase burguesa. Es una incongruencia descomunal pero ¡allí está! Es una verdad de hecho incuestionable. Entonces ¿Qué se desprende de lo anterior? Pues la importancia fundamental del trabajo asalariado como sostén del capital y de la sociedad burguesas y que su supresión o abolición concluiría inexorablemente en el desmoronamiento de las relaciones de producción y propiedad burguesas, ergo, mantener el trabajo asalariado es mantener las condiciones estructurales burguesas de producción, circulación y distribución. Abolir el trabajo asalariado es la clave de superación del capital. Esta es la teoría de Marx, asequible a quien quiera comprobarla mediante su estudio minucioso y su asimilación concienzuda.

La forma fundamental del trabajo burgués es la del trabajo asalariado (Tw) porque genera plusvalor. Sin trabajo asalariado no hay modo burgués (capitalista) de producción. Abolir el trabajo asalariado es la clave de superación del capital y de toda relación burguesa en la sociedad.

A mayor abundamiento del análisis de Marx transcribimos un fragmento de notable carácter teórico y analítico sobre el punto en cuestión:

"No se requiere una sagacidad fuera de lo común para comprender que, por ejemplo, si partimos del trabajo libre o del trabajo asalariado, que reconoce su origen en la disolución de la servidumbre de la gleba, las máquinas sólo podían surgir en oposición al trabajo vivo, como propiedad ajena a éste y (como un) poder que le es hostil; es decir, que se le tenían que contraponer en cuanto capital. E igualmente fácil de captar es que las máquinas no cesarán de ser agentes de la producción social cuando, por ejemplo, se conviertan en propiedad de los obreros asociados. En el primer caso, sin embargo, su distribución -es decir, el que las máquinas no pertenezcan al obrero- es igualmente condición del modo de producción fundado sobre el trabajo asalariado. En el segundo caso la distribución modificada partiría de una nueva base de la producción, de una base modificada, sólo surgida del proceso histórico" (Karl Marx Grundrisse; Siglo XXI, tomo 2, p. 396. Énfasis Marx)

Cadernos GPOSSHE On-line, Fortaleza, v. 2, n. Especial, 2019. 


\section{II}

\section{Socialismo: relaciones de producción y modo de producción}

¿Qué consecuencias de notable alcance, teóricas y políticas dejó, entre otras muchas, la Revolución Rusa de octubre para la práctica de la construcción del socialismo? No se puede negar el impacto histórico-mundial anti-burgués que produjo. $Y$ en particular el que provocara un estremecedor cambio en la sociedad rusa al eliminar la propiedad privada de los Mp de manos de los terratenientes y de la burguesía. ¿Quién o quiénes se apropiaron de esos Mp para que continuaran siendo utilizados en el proceso de producción? Pues, pasaron a constituir "propiedad del Estado Soviético", administrado éste por el PCUS; de este modo el Partido-Estado se erigió en "propietario" en nombre y representación de la clase proletaria y de su dictadura (Lenín dixit). Desapareció, pues, la clase propietaria burguesa que en sus miles y miles (quizás millones) de empresas tomaba sus decisiones de inversión, empleo y producción de acuerdo con su interés individual por las ganancias.

Consumada la desaparición, las miles y miles de decisiones diseminadas en el cuerpo burgués, quedó concentrada en una sola decisión y dirección: la planeación y el diseño centralizado en los órganos estatales y partidario, gestionados por millones de empleados ("afiliados" al Partido), quienes a su vez tenían voz de mando sobre la clase trabajadora propiamente dicha. En consecuencia los medios de producción (Mp) no eran propiedad de los trabajadores, eran una propiedad "ajena" (del Partido-Estado), que se le enfrentaban como "capital", no privado, sino "estatal", pero capital de todos modos; y la división del trabajo también se mantenía: trabajo de dirección y administración de los empleados que poseían las empresas con responsabilidades de gestión (trabajo administrativo), separado del trabajo manual de todo tipo y rama concentrado en la clase trabajadora.

Habían cambiado innegablemente las "relaciones de producción" pero no el modo de producción. Cambiaron las relaciones de producción capitalistas privadas, por las 
relaciones de producción capitalistas estatales, pero el modo de explotación del trabajo por el capital mediado por el salario no solo permaneció sino que se expandió. La economía de la URSS poseía el modo de producción y explotación del capital sin capitalistas privados bajo una nueva (inédita) relación de producción. Al igual que en la sociedad del capital, en la URSS el capital (estatal) no se apropiaba del trabajador sino de su trabajo, no inmediatamente sino por intermedio del pago monetario (salario).

¿Qué fue entonces lo que, finalmente, se construyó en la URSS como estructura socio-económica? No otra cosa que un sistema cuya naturaleza y características pueden ser resumidas del modo siguiente:

1) Producción de mercancías; producción de valor y de plusvalor. La reiteración continua era una reproducción de todo el proceso anterior: por tanto unidad de los procesos de producción y de circulación que constituían el ciclo global del capital estatal.

2) El resultado constante del proceso era el de producción-reproducción de masas de mercancías estatal-capitalistas, cuya estructura de valor consistía en: valor de $\mathrm{Mp}+$ valor de Ft + Plusvalor.

3) Todo el proceso económico era producción-reproducción constante de un excedente de valor $(\mathrm{Pv})$.

$\left.4^{\circ}\right)$ Las relaciones en todo el proceso entre trabajo, valor y producto, eran las siguientes: i) trabajo - plustrabajo; ii) valor - plusvalor; iii) producto - plusproducto. En todo estructuralmente idéntico al capitalismo.

5) Toda la estructura económica en su proceso ininterrumpido concluía en que la clase trabajadora rusa reprodujera la masa de mercancías $(m)$ y los medios de producción (Mp) como capital estatal y que el propio sistema reprodujera a la clase trabajadora como clase asalariada, por tanto como vendedora permanente de su Ft al Estado. Los trabajadores nunca dejaban de ser ;trabajadores asalariados! 
60) El proceso social producía y reproducía al Partido como propietario de los Mp, a la nomenklatura como poseedora-administradora de los mismos y a la clase trabajadora como no-propietaria.

$7^{\circ}$ ) El mecanismo socio-económico creado era más que solo un proceso "técnico" de producción-reproducción de mercancías valorizadas: era reproducción de la relación social productiva en general, esto es, aparato de reproducción que absorbía trabajo no pagado y por este medio transformaba los $\mathrm{Mp}$ en medios de generación-absorbción de trabajo impago (excedente)

8) Se mantenía constantemente las relaciones de distribución que le exigía su estructura asimétrica básica asentada en la no-propiedad de los trabajadores de los Mp y en la propiedad estatal: el valor del producto se distribuía como capital por un lado y por el otro los réditos o ingresos como salarios (w) y rentabilidad de las empresas estatales (excedente o plusvalor).

9) Todo el sistema, en definitiva, producía y reproducía, la separación siempre creciente, entre las condiciones objetivas del trabajo (Mp) y las condiciones subjetivas (Ft), transformando inevitablemente a las primeras en capital, y a las segundas en elemento de inversión dineraria (D) que no era sino una forma monetaria del capital estatal.

10) El proceso estatal-capitalista de la URSS producía y reproducía esa relación capitalista misma: en un polo el Partido como propietario capitalista efectivo y en el otro polo, la clase trabajadora como asalariada.

En tanto esta inmensa estructura socio-económica se mantuviera y se reprodujera (¡tal como se mantenía y reproducía!) en tales términos, no sólo no era socialismo lo que estaba "en construcción", sino que lo que hacía era ampliar el proceso de producción del capital y del trabajo asalariado; lo que estaba en construcción no era otra cosa que una variante capitalista de producción-reproducción. ¿Creaba acaso el trabajo asalariado en Rusia, el trabajo de la clase proletaria, propiedad para ella? No, exactamente igual 
que bajo el capitalismo privado, lo que creaba era capital, capital estatal, creaba un tipo de propiedad no burguesa que la explotaba y la mantenía como clase asalariada.

La teoría de Marx demuestra irrefutablemente que la relación entre el trabajador como trabajador asalariado y los medios de producción (Mp) como capital determina el carácter fundamental del modo de producción, de manera que los principales agentes de ese "peculiar" modo productivo que se construyera en Rusia, trabajadores y poseedores de Mp "en funciones" de capitalista (nomenklatura de planificación y de administración), aparecían como personificaciones de la estructura socio-económica como capital (estatal) y trabajo asalariado, siendo no otra cosa que encarnaciones de determinados caracteres sociales que el propio proceso social de producción le imprimía a los individuos participantes de tal relación; era pues en estas condiciones totalmente inevitable que se produjera en la URSS lo que se produjo: la emergencia real de la relación capitalista privada que era "asfixiada" por el Partido-Estado como propietario y por la burocracia etiquetada de servidores estatales del socialismo cuando solapadamente eran la proto-burguesía que exigía "abrirse paso" subvirtiendo una relación ficticia, formal, por lo que era en su sustancia.

Nada más alejado, entonces, de lo que se pregonaba, sostenía, creía y defendía desde las más altas instancias de la dirigencia partidaria como "socialismo"; a su vez, el marxismo también fue transformado: de teoría crítica de lo real se convirtió en una burda ideología a-crítica, abstracta, justificadora, y fetichística, exactamente con la misma función que tiene la ideología liberal bajo el dominio burgués. ¡No podía ser de otra manera! En la URSS cuajaba, se formaba, se desarrollaba una nomenklatura-burocrática, que ocupaba el lugar y tarea de una proto-burguesía "en funciones", era una figura capitalista embozada y al acecho dispuesta a dar el zarpazo jy así sucedió! La URSS no había abolido las contradicciones de clase, éstas estaban "disfrazadas" y "etiquetadas" como "socialismo realmente existente", lo que no era sino el "colmo" sarcástico de un socialismo realmente inexistente. 
Esto fue lo que se creó en la URSS desde sus inicios, por lo que pretender que se podían modificar políticas, cambiar dirigentes, "flexibilizar" mercados, dar más "libertad" de decisión a los administradores, etc. etc. como pedían los economistas en pro de un "socialismo de mercado", o bien "radicalizar" posiciones: menos autoritarismo partidario, "desburocratizar" el Estado, libertad de expresión, mejoras en derechos individuales, suprimir dogmatismos, etc. etc. exigencias todas de algunos políticos partidarios "democráticos y progresistas", no podía constituir ninguna orientación hacia un cambio verdadero que concluyera en socialismo, pues tales "reformas" no hubieran ido al fondo mismo de la estructura vigente: el trabajo asalariado vigente y su no abolición, o sea su perduración no su supresión.

Hubiera sido necesaria una nueva revolución encabezada por los trabajadores para salir de ese capitalismo, cosa ésta que no podía materializarse porque los trabajadores vivían y sentían que "eso" era "el comunismo" y deseaban vehementemente tumbarlo, derrocarlo, y "gozar del capitalismo occidental" y sus bondades. No había clase trabajadora revolucionaria y crítica, toda ella se oponía al "sistema comunista" bajo el que "sufrían"; revolución era igual a capitalismo occidental, su "confort" y consumo, para la masa de la población trabajadora.

\section{¿Qué es el modo de producción capitalista?}

Aunque parezca innecesario a muchos lectores, sin embargo, es preciso hacer una consideración crítica de lo que puede parecer trivial: que el proceso de producción es capitalista cuando:

19) la producción de mercancías, la producción del PBI en tanto que mercancía, ha adquirido la forma general del proceso de producción.

$\left.2^{\circ}\right)$ cuando el dinero, forma metamorfoseada de la mercancía, se cambia por la fuerza de trabajo ( $\mathrm{Ft}$ ) en tanto que mercancía y que, en consecuencia, el trabajo es trabajo asalariado. 
$\left.3^{\circ}\right)$ cuando, entonces, las condiciones objetivas, materia prima, materias auxiliares, herramientas, instalaciones, aparatos, maquinarias, etc. se concentran en pocas manos dejando de ser propiedad privada del trabajador individual y desde ese momento enfrentan al trabajador mismo como potencias autónomas, o sea como no-propiedad de los trabajadores, como propiedad ajena, por lo tanto como capital. Así "el capital" por su forma se "cosifica" en una relación determinada de enajenación socio-económica.

$4^{\circ}$ ) El trabajo como trabajo asalariado (condiciones subjetivas) y las condiciones objetivas del trabajo como capital, por tanto propiedad del capitalista, lo son como contraposición antagónica: no pueden existir el uno sin el otro.

De aquí que, si se expropia a los capitalistas y los medios de producción pasan a ser efectivamente propiedad de los trabajadores como trabajadores "asociados" y "dueños" de tales medios de producción de inmediato cesa el trabajo de ser asalariado y no se requiere abolición alguna mediante una decisión jurídico-política; el proceso deja de ser proceso capitalista de producción. Pero cuando esto no sucede, o sea, cuando se cumple sólo una parte de la expropiación (confiscación) y no la otra, o sea la apropiación de los medios de producción por parte de los trabajadores (eliminación del trabajo asalariado), pero se los concentra en el Estado, lo que se hace es dar lugar a una variedad de explotación asalariada de la Ft por una modalidad nueva que adquieren los Mp ahora como capital estatal: ¡no hay nueva sociedad, no hay socialismo! porque no hay modificación en el modo de producción; en consecuencia la consigna teóricopolítica de Marx revela toda su fuerza y esencia al no cumplirse la "supresión" del trabajo asalariado que es la conditio sine qua non para construir la nueva sociedad.

¿Qué enseñanza puede y debe desprender la clase trabajadora mundial de la experiencia histórica, extensiva a lo que aún hoy sucede en curso, China, Viet-Nam, Cuba, etc. abierta por la Revolución Rusa y la posterior construcción social? Pues, como se puede deducir lógicamente: cualquier cambio en las relaciones de producción de una sociedad, de una formación económico-social, no es de inmediato igual a cambio en el modo de producción. ¡Ahora puede entenderse! Las relaciones de producción atañen a las clases y sus vinculaciones mutuas en el proceso de producción-reproducción, el cambio de propietarios está en la base de la modificación de las relaciones de producción, 
pero, y he aquí lo importante: éstas pueden variar, modificarse, “dentro” del modo de producción.

Lo anterior implica en consecuencia que el "modo de producción" incluye sí necesariamente unas relaciones de producción específicas, pero las relaciones de producción no incluyen taxativamente sólo un modo de producción; ésto está claramente ejemplificado con la URSS: hubo sí un cambio de las relaciones de producción pero NO hubo cambio en el modo de producción. Es lo que permite explicarse rigurosamente el acontecimiento histórico-social de lo ocurrido en 1991: La URSS se desplazó de un capitalismo estatal hacia un capitalismo privado porque no había cambiado jamás el "modo de producción" del capital explotando el trabajo asalariado. De manera que iNo fue un cambio desde el socialismo hacia el capitalismo! Fue una modificación “dentro" del capitalismo, de un tipo de capitalismo por otro.

Es ésta una enseñanza teórica y política inconmensurable que la Revolución bolchevique y el proceso de construcción de la nueva sociedad lega a los trabajadores, que al no ser asimilada críticamente desde la propia experiencia, lo hecho se aceptó como de “buena ley" socialista y se extendió a todas las revoluciones posteriores que incurrieron exactamente en el mismo principio de separar capital estatal (Mp) y masa trabajadora no propietaria (Ft): no hay, no habrá, supresión definitiva del capitalismo sin abolir el trabajo asalariado; no hay socialismo sin que los trabajadores sean dueños efectivos de los Mp y se empeñen en edificar no sólo una nueva economía sino toda una nueva cultura y nuevos valores arrojando al basurero de la historia las relaciones de cálculo, mercantilización y acumulación privada de la riqueza que impone el capital. Nos enseña lo que los movimientos políticos populares, los procesos revolucionarios anti-burgueses llegados al poder, etc. deben hacer para no crear condiciones de una sociedad del capital con otra "denominación" que parece su opuesto pero que no muestra transformación a fondo en su carácter de nueva sociedad.

Pero además ¿dónde está escrito, quién demostró o quién estableció de modo inapelable que hay sólo un camino para el cambio social? ¿Quién, cómo y por qué fijó que los trabajadores "asociados" no son aptos para hacerse cargo del todo social y del desarrollo de las fuerzas productivas? iSi ya lo son bajo las actuales relaciones Cadernos GPOSSHE On-line, Fortaleza, v. 2, n. Especial, 2019. 
capitalistas de producción!! No sólo son aptos porque lo demuestran todos los días y la estructura social burguesa no duraría más de un día sin sus tareas de todo tipo, sino que deben soportar a una pequeña cúspide de indecentes, inútiles, corruptos, ociosos, licenciosos, y sus mayordomos representantes (la burocracia-poseedora de los Mp del EBG, Ejército Burocrático de Gestión), que cumple el papel de capitalista en "funciones" en nombre y representación de los rapaces rentistas propietarios, que se han vuelto muy onerosos para la consecución de un movimiento más sólido y seguro de la economía y su redistribución equitativa hacia todos quienes generan la riqueza que hoy todavía se la apropia esa casta de truhanes que es la burguesía imperialista, la que tiene a toda la sociedad sobre ascuas, al borde de cataclismos bélicos para dirimir conflictos de poder dentro de ella y desde ella contra los trabajadores. Los holgazanes inescrupulosos le declaran la guerra a quienes trabajan y sostienen la sociedad toda. ¡Lindo argumento burgués! Sostener que cuando los trabajadores "son asociados" para trabajar para una minoría infame bajo las órdenes de sus "lacayos" de administración, son mejores, más ordenados y más "productivos" que "asociados" para trabajar, producir y administrar para ellos mismos sin la férula de los holgazanes inescrupulosos.

"La abolición del trabajo asalariado" es proclamar un principio teórico como consigna política revolucionaria esencial para dilucidar claramente la diferencia fundamental entre capitalismo y socialismo, que se encuentra en toda la obra teórica económica y política de Marx desde 1848: "... detrás del derecho al trabajo está el poder sobre el capital, y detrás del poder sobre el capital la apropiación de los medios de producción, su sumisión a la clase obrera asociada, y por consiguiente, la abolición tanto del trabajo asalariado como del capital y de sus relaciones mutuas" (K. Marx - F. Engels; O.E. Tomo I, p. 157. Énfasis FHA).

Y para mayor ilustración sobre el tema y como para despejar probables dudas sobre la presencia e insistencia de la abolición del trabajo asalariado en Marx y en Engels, y enarbolarla cual consigna teórica y objetivo revolucionario de la clase trabajadora a lo largo de la vasta obra teórica de ambos, transcribimos algunos fragmentos de una serie de artículos que el último escribiera para un semanario de las Trade Unions titulado "The Labour Standard", que se publicaba en Londres. La 
colaboración de Engels, empezada el 7 de mayo terminó el 11 de agosto del mismo año de 1881, cuando el Jefe de Redacción del semanario le pidiera "suavizar" algunos pasajes que consideraba "demasiado fuertes"; la razón de fondo era que la publicación tendía a acomodarse a la política del Primer Ministro inglés Gladstone.

“...enterremos para siempre la vieja consigna (¡Salario justo por una jornada de trabajo justa! FHA) y sustituyámosla por otra: los medios de trabajo - materias primas, fábricas y máquinas- deben pertenecer a los obreros mismos". (F. Engels. Escrito el 1-2 de mayo de 1881.Publicado, como editorial, en el número 1 del periódico The Labour Standard).

"El capitalista se adueña de todo el producto (pagando de él al obrero) porque es el dueño de los medios de trabajo. Y por eso, la libertad real y efectiva de la clase obrera sólo será posible cuando sea propietaria de todos los medios de trabajo, de la tierra, las materias primas, las máquinas, etc., por tanto propietaria de todo el producto de su propio trabajo". (F. Engels. Escrito el 15-16 de mayo de 1881. Publicado, como editorial, en el número 3 del periódico The Labour. Standard. Londres, 21 de mayo de 1881).

"¿Debe ser ése el resultado final de todos estos trabajos, sacrificios y sufrimientos? (la lucha incesante para concluir en mantener la esclavitud asalariada FHA) ¿Debe ser ésa para siempre la aspiración más alta de los obreros británicos? ¿O la clase obrera de este país debe tratar, por fin, de evadirse de ese círculo vicioso y de encontrar la salida en un movimiento por la abolición del propio sistema de trabajo asalariado".

"Para lograr la representación completa de los obreros en el Parlamento, al igual que para preparar la abolición del sistema de trabajo asalariado, será necesaria la organización no por oficios separadamente, sino de la clase obrera como un todo. $Y$ cuanto antes se haga esto, tanto mejor. No hay en el mundo fuerza capaz de resistir un día siquiera a la clase obrera británica cuando ésta se encuentre organizada como un todo

Cadernos GPOSSHE On-line, Fortaleza, v. 2, n. Especial, 2019. 
único". (F. Engels. Escrito cerca del 20 de mayo de 1881.Publicado, como editorial, en los números. 4 y 5 del periódico The Labour Standard (Londres), 28 de mayo y 4 de junio de 1881).

"Ocurrirá una gran cosa: quedará roto el último eslabón que liga aún a la clase obrera de Inglaterra con la clase media de su país. Este eslabón era la tendencia conjunta al monopolio nacional. Una vez que quede destruido este monopolio, la clase obrera británica se verá obligada a tomar en sus manos sus propios intereses, a preocuparse de su propia salvación, y habrá de poner fin al sistema de trabajo asalariado. Confiemos en que no esperará hasta entonces". (F. Engels. Escrito a mediados de junio de 1881. Publicado, como editorial, en el número 7 del periódico The Labour Standard).

\section{¿Por qué es crucial la abolición del Tw?}

La abolición del Tw se convierte, de esta manera, en crucial para el tránsito hacia la construcción del socialismo, porque es la forma drástica y definitiva de cambio de las relaciones de producción del capital en un nuevo "modo" social de producción. ¿Cuáles son, efectivamente, sus características? Las siguientes:

$\left.1^{\circ}\right)$ Los trabajadores dejan de estar subsumidos al dominio del kapital, lo cual significa que éste ya no dirige ni ordena (directamente o por medio del Ejército Burocrático de Gestión, EBG) todo el proceso de producción/reproducción. Cesa el despotismo capitalista.

$2^{\circ}$ ) Los trabajadores dejan de ser vendedores del uso de su Ft. Ésta no es ya "mercancía". Por tanto se derrumba la invisible pero existente coacción económica sobre el trabajador.

3) Los Medios de producción (Mp) no se presentan más como capital sino como lo que son: ¡medios de producción! al servicio de los trabajadores como herramientas o medios para el autosustento y reproducción de los individuos y de la sociedad.

4) La relación monetaria que persiste, en un principio, entre trabajo y remuneración cambia. Los trabajadores no perciben ya un salario sino un ingreso, resultado del trabajo

Cadernos GPOSSHE On-line, Fortaleza, v. 2, n. Especial, 2019. 
colectivo y la distribución colectiva de las unidades productoras que los propios productores establecen y administran.

5o) El excedente social no adopta más la forma de plusvalor como apropiación del capital.

6) El proceso de producción, circulación y distribución, muestran ahora su carácter social sin opacidad, esto es, no están ya sujetos a la propiedad privada ni a su objetivo supremo de generar un plus como ganancia del kapital.

$7^{\circ}$ ) El conjunto del proceso social de producción deja de estar sujeto a la apropiación privada capitalista, la burguesía se ve impedida de sojuzgar y dominar a la sociedad.

8) Las relaciones monetarias y los Mp no aparecen como dominadores "naturales" de las relaciones sociales sino que son expresiones de ellas.

9) El trabajo ya no está ni formalmente ni realmente subsumido al capital.

De modo que, con la abolición del Tw se vuelve imposible mantener la propiedad privada capitalista; ésta se desploma como su consecuencia "natural" y ya no puede resurgir por más esfuerzo que pudiera hacer.

$\mathrm{Ni}$ en el caso de la ex-URSS ni en el de las actuales economías "socialistas" se puede encontrar nada de esto. Todas han sido y son, las que aún restan, variantes del dominio del capital sobre el trabajo: capital privado unas, capital público o estatal otras, ambas manteniendo el trabajo asalariado. El falso argumento esgrimido es el de que con los capitalistas "se desarrollan las fuerzas productivas", se debe alentar a los empresarios a "enriquecerse" para luego, siempre bajo la dirección del Partido, proceder a cambiar las reglas de juego a favor del socialismo. Tamaño desatino e ingenuidad pretende hacer pasar la dirigencia del Partido Comunista Chino como el de la construcción del "socialismo con características chinas", cuando lo que hace no es otra cosa que ¡capitalismo estatal chino!

Una característica de enorme importancia teórica y práctica sobre el tema, consiste en que la decisión de "abolir" el trabajo asalariado no puede ser sino obra de la propia 
clase trabajadora asalariada constituida en clase en el ejercicio del poder político. A diferencia de lo que ocurrió con la esclavitud y el trabajo servil, su liberación no será obra de otra clase propietaria que "cambia" el modo de explotación del trabajo pero no la explotación misma. Por esta razón es una finalidad que debe ser propuesta y materializada por la clase misma interesada en sacudirse el yugo económico de la clase capitalista, consigna que debe preceder y presidir toda acción político-práctica para su consecución.

"Toda la producción capitalista descansa en el hecho que el trabajo es directamente comprado para que en el curso de la producción sea apropiada una parte que no se compra pero que se vende en el producto - ésta es la razón de ser, el concepto mismo del capital-" (K. Marx, Théories I; p. 335. Énfasis Marx). Eliminado tal sostén la estructura toda de la explotación capitalista del trabajo se desploma inexorablemente.

\section{Oposición a la abolición desde la perplejidad}

Una de las primeras reacciones que provoca al lector (incluso del más culto) ante el planteo abolicionista es el de la perplejidad, para pasar luego, casi ipso facto, a hacerse preguntas en relación a: 19) lo estrafalario de la consigna, pagar/cobrar por trabajar es "normal y "natural"; $2^{2}$ ) los inmensos problemas que traería su implementación: desorden, caos, cada quien ¿qué haría? 3) ¿Cómo viviría la clase si no tiene adonde trabajar? 4) El ámbito del trabajo es la empresa privada/estatal ¿cómo se las arreglaría el trabajador para sostenerse él y su familia?

Preguntas todas pertinentes, pero todas asentadas en un fondo burgués de pensamiento: las empresas "dan" empleo, pagan un salario por trabajar, de ese modo se mantiene la familia, el trabajador puede avanzar en la escala social, se capacita, se desplaza en libertad sin prohibiciones, alcanza un nivel de consumo elevado, tiene cobertura médica y social, progresa en las empresas y en la sociedad, nadie pone trabas a personas con iniciativas y creatividad, se tiene libertad de decisión y de elección personal. Conclusión inexorable: ¿Quién quiere eliminar todas estas cosas? ¿hay algún demente que esté en contra de estas conquistas que han significado décadas y siglos de luchas, dolor y de muertes? Sin el salario ¿adónde irían los trabajadores? ¿Quién dará 
empleos y dinero? Sin la empresa, sin el capital, no puede haber progreso ni estabilidad social. La abolición del Tw es una locura de "visionarios" y "utopistas".

Ahora bien, ¿acaso el esclavo pensaba de otro modo que como él creía "ver" cuál era su situación y su propia interpretación refrendada por el discurso del propietario? ¿Qué pensaba sobre su situación, en relación a su amo, a su patrón, por ejemplo si éste prescindiera de él? Pues, entonces ¿qué sería de su suerte? ¿qué haría? ¿quién le "daría de comer"? ¿adónde iría en tal circunstancia? ¿dejar de ser esclavo? ¡pero qué locura es esa! ¿alguien quiere que muramos de hambre?

De la misma manera en el caso del trabajador servil: ¿qué haría si no pudiera trabajar la tierra, principalmente la del terrateniente? ¿adónde iría a dar con sus huesos? ¿cómo mantendría a su familia si el amo lo expulsara? ¿abolir la servidumbre? ¿dónde se ha visto tamaña tontería? ¿Quién desea que desaparezcamos?

Pues la historia se repite bajo el capitalismo. ¿Abolición del Tw? ¿pero de dónde sale semejante idea? Las clases sojuzgadas piensan sobre su situación desde las ideas de la clase opresora y desde lo que éstas le inducen a "ver" e "interpretar": sí, yo esclavo/siervo trabajo, pero el patrón "me da de comer" y el medio de cómo mantenerme. Sí, yo trabajo y percibo un salario, no le salgo gratis al patrón, no soy un esclavo, y soy libre de buscar otro empleo si lo quisiera, siempre habrá empresas en las cuales trabajar.

La base del juicio es exactamente la misma aunque las sociedades histórica y económicamente sean distintas. Pero puesto en estos términos históricos, la identidad es predominante sobre la alteridad. La identidad consiste en que todas son sociedades de clase: han cambiado las clases explotadoras y las clases explotadas, ipero sigue habiendo explotación del trabajo! La alteridad son los diferentes modos de la explotación por los diversos tipos de sociedades organizadas en la explotación del trabajo. El trabajo asalariado es una modalidad de explotación del trabajo por la cual la mayoría de la sociedad (Tw) trabaja para una minoría, exactamente de la misma forma que bajo el esclavismo y la servidumbre, en este sentido, el Tw en nada se diferencia de aquellas otras formas. 
He aquí algunas consideraciones pertinentes de E. Kant cuando, tratando de la Ilustración, se refería a "la pereza y cobardía" de muchos hombres para salir de su estado de sometimiento. De modo penetrante él decía que “... ¡Es tan cómodo no estar emancipado! Tengo a mi disposición un libro que me presta su inteligencia, un cura de almas que me ofrece su conciencia, un médico que me prescribe las dietas, etc., etc., así que no necesito molestarme. Si puedo pagar no me hace falta pensar: ya habrá otros que tomen a su cargo, en mi nombre, tan fastidiosa tarea. Los tutores, que tan bondadosamente se han arrogado este oficio, cuidan muy bien que la gran mayoría de los hombres (y no digamos que todo el sexo bello) considere el paso de la emancipación, además de muy difícil, en extremo peligroso. Después de entontecer sus animales domésticos y procurar cuidadosamente que no se salgan del camino trillado donde los metieron, les muestran los peligros que los amenazarían en caso de aventurarse a salir de él. Pero esos peligros no son tan graves pues, con unas cuantas caídas, aprenderían a caminar solitos; ahora que, lecciones de esa naturaleza, espantan y lo curan a cualquiera las ganas de nuevos ensayos.

Es, pues, difícil para cada hombre en particular lograr salir de esa incapacidad, convertida casi en segunda naturaleza. Le ha cobrado afición y se siente realmente incapaz de servirse de su propia razón, porque nunca se le permitió intentar la aventura. Principios y fórmulas, instrumentos mecánicos de un uso, o más bien abuso, racional de sus dotes naturales, hacen las veces de ligaduras que lo sujetan a ese estado. Quien se desprendiera de ellas apenas si se atrevería a dar un salto inseguro para salvar una pequeña zanja, pues no está acostumbrado a los movimientos desembarazados. Por esta razón, pocos son los que, con su propio esfuerzo y espíritu, han logrado superar esa incapacidad y proseguir, sin embargo, con paso firme". (E. Kant, Filosofía de la Historia; FCE, 1979, pp. 25-27)

Claro es que Kant aboga por la libertad de "pensar" y obrar de acuerdo con la "razón" oponiéndose a las imposiciones de los poderes; esa es la libertad y la racionalidad que la llustración suministra en el siglo XVIII a quienes, en la Alemania, escindida en multiplicidad de pequeños Ducados y Condados, siente temor de dar el gran paso de “...servirse de su propia razón”. Por supuesto el gran paso real era el de la acción para 
sacudirse el yugo de la nobleza. Pues bien, ahora ha llegado el momento histórico de sacudirse el yugo construido por la burguesía para con los trabajadores asalariados, y muchos de los propios explotados y sus mejores líderes "sienten temor de "salir de esa incapacidad, convertida casi en segunda naturaleza"

Punto central entonces: La pregunta fundamental no es la que se formulaban (figuradamente claro está) el esclavo y el siervo: o sea ¿Quién me dará de comer si no es el amo para quien trabajo? sino su opuesta ¿Cómo hará el amo para comer y vivir sin el trabajo esclavo y el del siervo? ¡Esta es la verdadera pregunta! Y son los amos los que se la tienen que hacer no los trabajadores en lugar de aquellos; los trabajadores no han tenido ni tienen por qué hacerse cargo de las angustias de las clases explotadoras cuando éstas vayan a perder sus privilegios al carecer de trabajadores que trabajen para ellas y no para sí mismos. El trabajador siempre está en condiciones de ¡trabajar! Los miembros de las clases propietarias, en el caso de la emancipación social del trabajo, pues, tendrán que trabajar si quieren comer jeso es todo! Pero no es a lo que están dispuestas, de allí la oposición, la guerra, las mentiras, las muertes. Pasa lo mismo para el trabajo asalariado: la cuestión no es ¿quién me dará empleo? sino ¿cómo hará para vivir y comer el capitalista cuando otros no trabajen ya para él? ¿cómo hará para seguir siendo "rico" si no tienen "pobres" que lo sirvan, atiendan y trabajen para él? ¿Y adónde irán su patrimonio personal, su propiedad y el excedente apropiado de modo privado? Sencillamente a manos... ¡de los trabajadores! El patrimonio personal se habrá transformado en colectivo, la propiedad será social y el excedente será apropiado y distribuido conforme a las nuevas leyes de la nueva sociedad, por tanto de acuerdo con las decisiones de quienes los producen.

Y sí, lamentablemente muchas personas cultas y políticamente conscientes se asustan y parecen retroceder espantadas ante el planteo; cuando a poco se van quedando sin fundamentos y ven que deben aceptar la consigna, les llega otra vez el freno: ¿ y los problemas, los obstáculos, la guerra que eso desataría, etc. ¡Y claro que es así! ¿o abolir el esclavismo y la servidumbre fue un camino de rosas y se abolieron de forma armónica y concertada entre "hombres sabios"?

III

Cadernos GPOSSHE On-line, Fortaleza, v. 2, n. Especial, 2019. 


\section{La abolición del Tw y el movimiento comunista internacional}

"En vez del lema conservador de " $i$ un salario justo por una jornada de trabajo justa! deberá inscribir en su bandera esta consigna revolucionaria: jabolición del sistema del trabajo asalariado!" (Marx-Engels, O.E. Moscú. "Salario, precio y ganancia", p. 434)

La consigna teórica-política del epígrafe no fue recogida por los movimientos políticos socialistas revolucionarios en sus Programas y documentos liminares ni antes de asumir el poder político ni tampoco una vez asumido el mismo, planteándolo al menos como objetivo ineludible y definitivo una vez superadas las instancias político-sociales más duras en la construcción económica de las nuevas relaciones.

En el Preámbulo de la Constitución cubana de 1976, por ejemplo, se puede leer en un fragmento: "De que sólo en el socialismo y el comunismo, cuando el hombre ha sido liberado de todas las formas de explotación: de la esclavitud, de la servidumbre y del capitalismo, se alcanza la entera dignidad del ser humano; y de que nuestra Revolución elevó la dignidad de la patria y del cubano a superior altura". Se refiere a la liberación de todas las formas de explotación: de la esclavitud, de la servidumbre y... del capitalismo ¿cómo del capitalismo? La frase debería terminar "y del trabajo asalariado" ya que así lo exige la lógica del razonamiento. Para que pueda tener sentido y consistencia lógica la referencia al "capitalismo" debería decir entonces que: “... cuando el hombre ha sido liberado de todas las formas de explotación: del esclavismo, del feudalismo y del capitalismo", tal como está la redacción parece expresar todo un síntoma de inconsciencia teórica: la ausencia sobre el tema decisivo del trabajo asalariado en los procesos de cambios sociales de la lucha socialismo versus capitalismo que caracteriza la historia humana de este último siglo.

Se vuelve notoria y llamativa, entonces, esa ausencia del concepto central que determina sin ambigüedad la superación de la sociedad burguesa: abolición del trabajo asalariado, porque tal como las experiencias más importantes de cambio socialistas muestran (URSS; China, países socialistas europeos post-segunda guerra mundial), 
eliminar la propiedad privada capitalista es una condición necesaria importantísima pero no es suficiente; concentrar la propiedad en el Estado y continuar con el trabajo asalariado se ha revelado como una modalidad de concentración y acumulación de capital que finalmente pugna por recrear la clase burguesa y la propiedad privada tanto fuera del Estado como de la misma propiedad pública, aun cuando al sistema se lo etiquete de socialista; en cambio la abolición del Tw significa quitar la base fundamental sobre la que se estructura el modo de producción capitalista y abrir la transición al "modo de producción del trabajo asociado" como lo teorizó Marx.

Sin el trabajo asalariado (Tw) la sociedad burguesa y el capital se desploman, son imposibles; confiscando la propiedad privada sin abolir el trabajo asalariado, el resurgimiento del dominio burgués acecha de manera constante y objetiva. La estructura social real que genera ese "resurgimiento" consiste en: mantener la escisión entre propiedad y trabajo. La propiedad estatal definida como propiedad "social" es una modalidad de acumulación de capital: en un polo se concentran los medios de trabajo, medios de producción (Mp), medios de subsistencia y del patrimonio dinerario en manos de los no-trabajadores (Estado-dirigencia gobernante), y en el otro polo se concentran los trabajadores como no-propietarios de hecho, quienes sí ponen en movimiento todo el andamiaje inerte de las condiciones objetivas del proceso de producción; el trabajo vivo de la clase asalariada (Tw) inyecta la savia que fructifica en la masa de productos finales y su valorización.

¿Cuál puede ser la razón tan poderosa de esta ausencia por la que en toda la historia del Movimiento Comunista Internacional no aparezca bajo ningún concepto el objetivo histórico revolucionario fundamental para la superación irreversible de la sociedad burguesa: la abolición del trabajo asalariado? El quid no puede residir sino en una clave histórico-política de importancia mayúscula que el análisis de clase no puede dejar a un lado: las luchas contra la burguesía, el capital y el imperialismo, desde hace un siglo, aparecieron, triunfaron y luego retrocedieron en los países y regiones periféricas del capitalismo central, esto es, no en las sociedades más desarrolladas, con un proletariado maduro políticamente, socialmente extendido y liderando las luchas, sino en las sociedades más atrasadas. 
En aquellos países en que triunfaran las fuerzas proletarias (Rusia, China, Cuba, Viet-Nam, Corea del Norte, Yugoslavia, etc.), las dirigencias debieron hacerse cargo ineludiblemente de la planificación y desarrollo de las nuevas relaciones sociales en condiciones de inferioridad económica, técnica, científica y de escasa fuerza proletaria en la estructura de la sociedad.

Se imponía entonces construir aceleradamente las condiciones materiales para suturar la brecha económica respecto del capitalismo más avanzado, generando y expandiendo además la clase social trabajadora portadora de los cambios puesto que en tales países existía el predominio del campesinado y la pequeña burguesía urbana antes que el proletariado asalariado; otras eran las tareas inmediatas e impostergables antes que proceder a la abolición del Tw cuya dimensión socio-económica era muy exigua. Pero este objetivo nunca debió desaparecer para llevar a cabo la construcción de la nueva sociedad.

Es una situación histórica extremadamente curiosa: ni Lenín, Trotsky, Bujarin, Preobrazhensky, Luxemburgo, Gramsci, Lukács, sólo para hacer mención de los más grandes pensadores y actores del marxismo teórico-revolucionario, señalaron y propusieron esta clave decisiva para suprimir la burguesía y el capital a partir de haberse quebrado la cadena imperialista por su eslabón más débil: Rusia. Repasando la historia de lucha de los pueblos y sus dirigencias en los procesos anti-capitalistas el peso mayor de la consigna fue: jexpropiación de los expropiadores! Sin alusión alguna a la cuestión del trabajo asalariado y su abolición.

Es claro que si se expropia a los capitalistas y los medios de producción pasan a ser efectivamente propiedad de los trabajadores como trabajadores "asociados" $y$ "dueños" de tales medios de producción de inmediato cesa el trabajo de ser asalariado y no se requiere abolición alguna mediante una decisión jurídico-política; el proceso deja de ser proceso capitalista de producción. Pero cuando esto no sucede, o sea, cuando se cumple sólo una parte de la expropiación (confiscación) y no la otra, o sea la apropiación de los medios de producción por los trabajadores (eliminación del trabajo asalariado), pero concentrándolos en el Estado, lo que se hace es dar lugar a una variedad de explotación asalariada de la Ft por una modalidad nueva que adquieren los 
Mp ahora como capital estatal: ¡no hay nueva sociedad, no hay socialismo! porque no hay modificación en el modo de producción; en consecuencia la consigna teórico-política de Marx revela toda su fuerza y esencia al no cumplirse la "supresión" del trabajo asalariado.

\section{Abolición del Tw como concepto concreto}

Ahora estamos en condiciones de advertir que el cambio de la situación del trabajador en el proceso de producción i.e. la eliminación de su carácter de asalariado por tanto de no-propietario de Mp bajo el capitalismo, ipso facto implica la mutación completa en la propiedad de aquellos $\mathrm{Mp}$ porque sin el Tw el capital sería nada, sin la subsunción del trabajador al capital no habría propiedad privada capitalista. Plantearse las cuestiones referidas a la propiedad (expropiar, confiscar) del capital pero continuar con el Tw es un paso adelante sin dudas, pero sólo un paso y de lo que se trata es de dar el paso que asegure el tránsito hacia adelante y no recreando condiciones para retroceder: sólo la abolición del Tw asegura tal paso y al mismo tiempo la imposibilidad de su retroceso ¿Por qué? Porque la mutación del trabajador de asalariado en asociado implica el cambio de las relaciones de propiedad y de producción; eliminar la propiedad privada capitalista reemplazándola por la propiedad estatal siguiendo con el Tw, repetimos, es mantener una variedad de propiedad privada que lleva indefectiblemente a que los Mp sigan siendo capital y a que quienes los administren se resuelvan en propietarios y entonces todo marche hacia atrás.

La abolición del Tw es la clave de superación de la sociedad burguesa y del dominio del capital sobre ella porque contiene el cambio de los trabajadores como no propietarios en trabajadores asociados como propietarios, estos y no el Estado propietario es el auténtico cambio en la formación económico-social. Lo cual permite entender porque cuando se acomete el estudio y exposición del paso de una sociedad a otra se pierda el rumbo ocupándose detalladamente a veces de cuestiones como la "administración", la "gestión" de la propiedad (del Estado, comunales, cooperativas, etc.) pero nada se dice sobre qué pasa con el Tw. Esto se desliza inadvertido e inabordado. Abolición del Tw es el concepto concreto que concentra la llave maestra para examinar 
lo demás problemas de la transición con claridad meridiana ordenando el cuadro fundamental de decisiones políticas y económicas de los procesos revolucionarios antiburgueses.

Este aspecto de "concepto ausente" es posible de ser advertido en un fragmento notable de F. Engels en el Resumen que él mismo redactara de una parte de su AntiDühring bajo el título "Del socialismo utópico al socialismo científico", texto éste leído por millones de lectores en el mundo, y mucho más leído que el propio Anti-Dühring; en el penúltimo párrafo subtitulado "Revolución proletaria" dice que es la "...solución de las contradicciones: el proletariado toma el poder político $y$, por medio de él, convierte en propiedad pública los medios sociales de producción, que se le escapan de las manos a la burguesía. Con este acto, redime a los medios de producción de la condición de capital que hasta allí tenían y da a su carácter social plena libertad para imponerse. A partir de ahora, es ya posible una producción social con arreglo a un plan trazado de antemano. El desarrollo de la producción convierte en un anacronismo la subsistencia de las diversas clases sociales. A medida que desaparece la anarquía de la producción social, va languideciendo también la autoridad política del Estado. Los hombres, dueños por fin de su propia existencia social, se convierten en dueños de la naturaleza, en dueños de sí mismos, en hombres libres" (F. Engels, "Del Socialismo utópico al socialismo científico"; Editorial Progreso, Moscú, 1966, p. 153). Por supuesto que en el pensamiento de Engels está el que los medios sociales de producción dejen de ser capital cuando sea haya abolido el trabajo asalariado, pues de lo contrario no podrá transformarse la propiedad privada capitalista en propiedad social y el trabajo obrero en trabajo asociado ni tampoco, por tanto, la desaparición de las clases, pero no está explícitamente formulada, no figura contundentemente como la pre-condición esencial para que la revolución proletaria alcance la superación de la sociedad del capital, es un concepto ausente.

Emprender la abolición del Tw a fondo, es lo que despeja de una vez por todas el proceso de producción como proceso social al hacer que desaparezcan el capitalista y el capital porque los trabajadores ya no trabajan para aquellos, ya no son "expropiados"; claro es ahora que los trabajadores, en las nuevas condiciones, se enfrentan a una novísima situación: trabajar de modo asociado, sin órdenes, planes, objetivos de 
producción, venta, ni vigilancia ajena, y que las nuevas entidades laborales se articulen en una nueva estructura socio-productiva como una sola potencia colectiva mediante órganos de planeación local - provincial - nacional, recogiendo en herencia los avances que en estas materias se realizaron bajo la "antigua sociedad"; pero no menos cierto será que ahora los nuevos "propietarios" se enfrentarán a, porque surgirán inevitablemente, "nuevos" problemas, nuevas incógnitas, nuevos modos de organización productiva, de capacitación, de gestión, que exigirán "nuevas respuestas" que hoy no se pueden sino mencionarlas como tanteos y búsquedas, siendo ocioso y sin sentido querer detallarlas. Se tratará de otra lógica social y productiva.

Que el capital dominara y sometiera al Tw le demandó a la burguesía siglos de conflictos y convulsiones socio-políticas hasta poder "pararse" sobre sus propias fuerzas económicas y erigirse en dueña y señora de la sociedad; y para hacerlo, paralelamente a la penetración de las viejas formas feudales de producción por medio del dinero y del comercio, debió ir subvirtiendo precisamente esas formas por sus propias formas de producción burguesas: liberar al trabajador de las cadenas de la esclavitud y de la servidumbre para ponerlo a disposición de su propia estructura de subordinación y de producción. Es éste el punto clave del cambio social: el cambio en la organización del trabajo, que es el cambio de las relaciones de producción.

Digamos además que la burguesía, social e históricamente, provenía de los bajos fondos del medioevo, era despreciada, discriminada, insultada, injuriada por ocuparse de tareas indignas de los hombres nobles y de las altas esferas sociales; plebeya, maloliente, soez, rústica, disolvente y al mismo tiempo altisonante y pretenciosa; en sus momentos de mayor empuje y enriquecimiento para quitarse todas aquellas ofensas se dedicaba a "comprar" títulos de nobleza y en algunos casos convertirse en "prestamista" de Monarcas y aspirantes a serlo, como también de dignatarios eclesiásticos y hasta del mismo Papa. Dicho de otro modo: la burguesía que hoy se ve no produjo un cambio cultural fulminante y eficaz de inmediato; no fue siempre perfumada, organizada, eficiente, culta, elegante, pundonorosa y sobre todo "exitosa": todo esto vino con el tiempo, el dinero y el aprendizaje contra propios y extraños de cómo moverse, pero desde 
sus humildes y bajos orígenes fue siempre tramposa, cínica, sanguinaria, criminal y ladrona.

Pues bien, de la misma manera ocurrirá con los trabajadores asociados sin pizca de asalariado; abrirán éstos una nueva etapa, una nueva cultura de relaciones humanas, compleja, extendida en el tiempo y plena de interrogantes impensados hoy, de avances y retrocesos, pero en la cual nada habrá de irresoluble, los trabajadores en esas nuevas condiciones construirán nuevas soluciones; después de todo deberán hacer como hizo la burguesía y como hace siempre la humanidad ante las encrucijadas socio-históricas: ¡on s'engage et puis on voit! (Napoleón), algo así como "nos lanzamos a la lucha y luego vemos". Lo que los hombres hacen, son los hombres quienes deshacen para volver a hacer otras nuevas relaciones que son las que avizoran y construyen lo porvenir, no existe predestinación sobrehumana (divina) ni natural.

\section{Bibliografía}

Marx, Karl; El Capital. Crítica de la Economía Política; Siglo XXI Editores, 1975.

Elementos fundamentales para la crítica de la Economía Política (Grundrisse); Siglo XXI Editores, 1971

Teoría sobre la Plusvalía; FCE, 1980.

Théories sur la Plusvalue; Editions Sociales; París, 1974.

Marx, Karl - Engels, Federico; Obras Escogidas en dos tomos; Editorial Progreso; Moscú; 1966

Engels, Federico; Anti-Duhring; Editorial Grijalbo, México, 1964.

Kant, Emmanuel; Filosofía de la Historia; FCE, 1979.

Lenín, Vladimir Ilich; El Estado y la Revolución; Obras Escogidas; Editorial Progreso, Moscú, 1960.

Madrid Cobeña, Luciana - Azcurra, Fernando Hugo; La abolición del trabajo asalariado; Ediciones Cooperativas; Bs. As. 2017.

Cadernos GPOSSHE On-line, Fortaleza, v. 2, n. Especial, 2019. 
Cadernos GPOSSHE On-line, Fortaleza, v. 2, n. Especial, 2019. 